\title{
Collaborative Learning of Usability Experiences: Improving UX Training THROUgh EXPERIENTIAL LEARNING
}

\author{
Audrey Girouard ${ }^{1 *}$, Robert Biddle ${ }^{1}$,Sonia Chiasson ${ }^{1}$, Stephen Fai ${ }^{1}$, Lois Frankel ${ }^{1}$, T.C. Nicholas Graham ${ }^{2}$, \\ Chris Herdman ${ }^{1}$, Bill Kapralos ${ }^{3}$, Alex Ramirez ${ }^{1}$ \\ ${ }^{1}$ Carleton University, ${ }^{2}$ Queen's University, ${ }^{3}$ University of Ontario Institute of Technology \\ *audrey.girouard@carleton.ca
}

The Collaborative Learning of Usability Experiences (CLUE) training program ${ }^{1}$ is an NSERC CREATE grant that trains Canada's leaders in HCI. We aim to improve our trainees' capabilities across the disciplinary boundaries (Information Technology, Psychology, Computer Science, and Design), through collaborative professional skills development, experiential learning, and technical skills.

Within human computer interaction (HCI), usability professionals employ research-based methods and principles to understand users' conceptual models of tasks and design interfaces and experiences accordingly. There is an increased demand for skills in usability experience (UX) design and testing, yet we identify a lack of training in these skills in current graduate programs across Canada. Even in the context of multidisciplinary $\mathrm{HCI}$ programs, graduates often face a usability knowledge gap, which may be due to a lack of grounding in real-world contexts, without business constraints.

Through the CLUE training program, we alleviate the gap by providing opportunities for students to experience the usability process on real projects. We produce a new hybrid of trainees who can more effectively apply usability skills and research current systems as a result of real-world experience. We have trained 72 students in the last three years.

The enriched CLUE learning program is facilitated through five main activities delivered by academics and external industry experts:

- Workshops offer hands-on practice and professional skill development to our graduate students. Examples include "Crowdsourcing and Usability"; or "Creating Transparency in Design Study Research".

- Mini-courses deliver theoretical and technical content knowledge. Examples include "Introduction to Physical Computing"; or "GUI Programming with Python and Tkinter".

\section{${ }^{1}$ https://carleton.ca/clue/}

CEEA19; Paper 001

University of Ottawa; June 9-12, 2019- 1 of 1 -
- A Seminar series exposes students to cutting-edge research in HCI and industrial case studies.

- Our annual Symposium brings together students, partners, and the community to share practical experiences in leadership and communication through two-minute lightning talks and posters, and develop professional skills with networking events.

- The training culminates with a UX based Internship with our industry or government partners (520 hours). Afterward, students lead a peer workshop, allowing them to share their own learning outcomes and teach professional skills acquired experientially.

After being exposed to the theory, directly engaging with a practical, real-life example provides students with a greatly needed experiential form of learning. The 52 internship placements completed to date have been broadening: students learn about applying the dominant HCI skill (design, programming, etc.) as well as how they are integrated into the workplace. Employers have recognized the worth of the CLUE training: our industry partners have hired a large majority of our students, with jobs often secured before the end of their degree.

The CLUE training program enhances students' education and training, ultimately increasing their attractiveness to Canadian industry due to this added quality exposure to the real world. Insights from the training program include the benefit of: 1) scaffolding internships with other learning activities; 2) promoting a sense of community among students by sharing their own experiences; and 3) offering opportunities to interact directly with UX industry to give students a realistic view of expectations and how to best prepare for a career. 